【論文】

\title{
集束イオンビーム照射を受けた 多層カーボンナノチューブの熱伝導 \\ Thermal Transport in an Individual Multi-Walled Carbon Nanotube Defected by Focused Ion Beam Irradiation
}

\author{
梄㠃将弘* 生田竜也** 西山貴史** 高橋厚史**,*** \\ Masahiro Narasaki, Tatsuya Ikuta, Takashi Nishiyama, and Koji Takahashi
}

\begin{abstract}
1 本の多層カーボンナノチューブ（MWNT）の狙った位置に集束イオンビーム（FIB）を段階的に照 射しながらその熱抵抗を計測し，FIB 照射による MWNT のアモルファス化が熱輸送に与える影響を 調べた．複数の試料で FIB 照射の位置を変えて計測したところ, 熱抵抗の増加量はすべて 1 回目の照 射時が最も大きく，照射回数が増えるにつれてその増加量は減少する傾向が得られた。この結果はナ ノスケールの材料の熱輸送は拡散的ではなく, フォノンの弾道性を考慮しなければならないことを示 しているが，同時に熱伝導率が長さのべき乗に比例するという単純なモデルでは説明できないことも 示している.
\end{abstract}

We conducted measurements of the thermal resistance of individual multi-walled carbon nanotubes (MWNT) defected by focused ion beam (FIB) irradiation to investigate the effect of amorphization of ballistic thermal transport. Obtained results for three samples with many kinds of irradiated points show that the first irradiation gives the largest thermal resistance and the resistance added by each FIB irradiation decreases as the number of defects increases. This result suggests that the thermal transport in nanoscale material is not diffusive but the simple model does not hold, that the thermal conductivity is proportional to power-law of length.

[Keywords: Thermal resistance, Focused ion beam, Multi-walled carbon nanotube]

\section{1.はじめに}

熱輸送キャリアの平均自由行程と同程度のサイズのマ イクロ・ナノスケールの材料では, その熱伝導率にサイズ 効果が現れる.これは, フォノン輸送では, 材料の境界で の散乱によってフォノンの自由行程が制限され短縮され るためと解採できる．例えば，カーボンナノチューブ (CNT) [1,2]や SiGe ナノワイヤ[3]において，バルク材料

* 九州大学大学院工学府航空宇宙工学専攻, †819-0395 福岡市 元岡 744 番.

Dept. of Aeronautics and Astronautics, Fac. of Engineering, Kyushu University, 744 Motooka, Fukuoka 819-0395.

FAX: 092-802-3017 E-mail: takahashi@aero.kyushu-u.ac.jp

** 九州大学工学研究院航空宇宙工学部門, $\bar{T} 819-0395$ 福岡市 元岡 744 番.

Dept. of Aeronautics and Astronautics, Fac. of Engineering, Kyushu University, 744 Motooka, Fukuoka 819-0395.

FAX: 092-802-3017 E-mail: takahashi@aero.kyushu-u.ac.jp

*** 九州大学カーボンニュートラル・エネルギー国際研究所, T819-0395 福岡市元岡 744 番.

International Institute for Carbon-Neutral Energy Research (WPII2CNER), 744 Motooka, Fukuoka 819-0395.

FAX: 092-802-3017 E-mail: takahashi@aero.kyushu-u.ac.jp
では見られない熱輸送のサイズ効果が実験から報告され ており，理論的予測[4-6]を裏付けることがようやくでき つつある。

高発熱密度化の進むデバイスにおける熱の問題を, マ イクロ・ナノスケールの材料によって解決する際には, こ のようなフォノンによる熱輸送のメカニズムを正確に把 握しておく必要がある. CNT はグラフェンを円筒状に丸 めた構造をしており，その円周方向には境界が存在しな

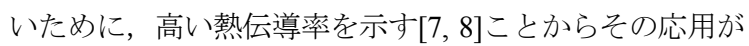
期待されているが, 特に多層カーボンナノチューブ （MWNT）におけるフォノン輸送については未だよくわ かっていない.

単層カーボンナノチューブ (SWNT) は単純な構造であ るためによく取り扱われており, 理論的な研究から, 数百 $\mathrm{nm}$ の領域での弾道的な熱輸送の存在[4]や, 弾道的な熱輸 送から拡散的な熱輸送への遷移 $[5,6]$ が報告されている.

一方, MWNT の理論研究は数が少なく, 実験的な研究か ら, フーリエの法則の破綻, すなわち熱伝導率が試料長さ によって変化するということ[1]や， $5 \mu \mathrm{m}$ までの弾道的な 熱輸送の存在[2]が報告されている.しかしながら,これら 
の結果は室温で $50 \mathrm{~nm}$ 程度と推測されるフォノンの平均 自由行程[9]を大きく上回った領域であり，単なるフォノ ンの弾道性だけでは理解しがたい, 一体, どれほどの長さ の自由行程を持つフォノンがどれほど熱輸送に寄与する のか，さらにどれほどの長さの試料になると拡散的な熱 輸送の領域に到達するのか, という重要な議論が MWNT に関しては未だ不十分である.

本研究では, フォノン輸送のメカニズムの調查を目指 した Hayashi らの研究[2]において, MWNT 内の熱輸送が 長さ $5 \mu \mathrm{m}$ においても弾道的な傾向を示したままとなって いる原因について探求する, 寸なわち， $5 \mu \mathrm{m}$ 以上の領域 でも弹道的な熱輸送が続くのか，それとも弾道性では説 明できない別の現象が起こっているのかを調査すること を目的として, 長さ $10 \mu \mathrm{m} の \mathrm{CNT}$ の熱伝導率の計測を集 束イオンビーム (FIB) の照射と組み合わせて行った. FIB 照射によるアモルファス化によって MWNT 上の狙った 場所でフォノン散乱を引き起こし，その試料の熱抵抗を 調查するという作業を交互に繰り返すことで, 照射回数 に対する熱抵抗の変化を得た．以下にその詳細を述べる.

\section{2. 実験}

\section{1 実験試料・装置}

本研究では保土谷化学工業株式会社製の MWNT を試 料とした. 熱抵抗の計測には Fujii ら[8]が開発した $\mathrm{T}$ 字一 体型センサを用いた. センサについては 2.3 に後述する. 熱抵抗計測と $\mathrm{Ga}^{+}$の FIB 照射はFIB と SEM を共に備えて いる Versa3D（FEI Co., Hillsboro, OR, USA）のチャンバー 内で行った.この装置はSEM による FIB 照射の位置合わ せが可能なので，狙った箇所以外の FIB によるダメージ を回避できる. FIB 照射によって MWNT はアモルファス 化することが知られているが，その評価には高解像度 TEM（JEM-3200FSK）を用いた。

\subsection{FIB 照射による欠陥の評価}

MWNT に FIB を照射したときのアモルファス化の大き さの均一性を評価した.この評価は, 本研究の特徴である FIB 照射による MWNT のアモルファス化がもたらす熱輸 送への影響を考察する際に必要となる. なお，この評価用 試料は計測用試料とは別のものである.

超音波で分散させた MWNT を TEM 用銅グリッドの上 に滴下し, 図 1 に示したように 1 本の MWNT 上の 8 ケ
所に $\mathrm{Ga}^{+}$が照射されるように FIB を走查した（加速電圧： $30 \mathrm{kV}$, ビーム電流 : $1.6 \mathrm{pA}$, ドーズ量 : 約 $\left.9 \mathrm{pC} \cdot \mu \mathrm{m}^{-2}\right)$. 図中の 8 本の白線は矩形として設定した照射領域 $(0.1$ $\mu \mathrm{m} \times 20 \mu \mathrm{m} ）$ を表しており，領域内を蛇行するように走査 を行った. この際，ビーム $(\varphi 7.1 \mathrm{~nm})$ のオーバーラップ 值を $\mathrm{X}, \mathrm{Y}$ 方向ともに 50 \%に設定しており，それぞれの ビームはビーム径の半分が重なるように照射している. 8 ケ所すべて照射後に TEM 観察を行った.

図 2 は FIB 照射による変化を調べるために, 図 1 の MWNT を横から観察した TEM 画像である。（a）は図 1 における照射位置 1st，2nd，3rd の TEM 画像であり，斜 線部はFIB 照射によってアモルファス化した箇所(以降, 欠陥，または結晶構造が残っている箇所と合わせて欠陥 部と呼ぶ）を表す。（a）の下に示すイラストは, FIB 照射 によって等分割された MWNT の熱抵抗は等しく,さらに, 以下で述べる理由から, 久宿部の熱抵抗はす心゙て等しい と考えたときの熱抵抗の直列接続を表す。（b），（c）， (d) は照射位置 2nd を拡大したもので, MWNT の層の模 様が消えていることが確認でき，これらから久陷が確認 できた. 直径 $104 \mathrm{~nm}$ の MWNT の 8 ケ所の照射位置にお いて，図 2 の(b), (c)の結晶部とアモルファス部の境界の 距離から見積もった欠陥の軸方向長さは $130 \sim 145 \mathrm{~nm}$ ，そ して MWNT の断面においてその結晶構造が残る部分は 弓型と考えて, その高さを図 2(d)の境界から決定し, 欠陥 が断面積に占める割合を $81 \sim 92 \%$ 見積もった．今回の 条件では同一の MWNT における久陥の大きさのばらつ きは 1 割程度であることがわかった.これは MWNT の断 面積が厳密には一定ではないということと FIB の焦点合 わせの度合いの違いによるものと考えられる。

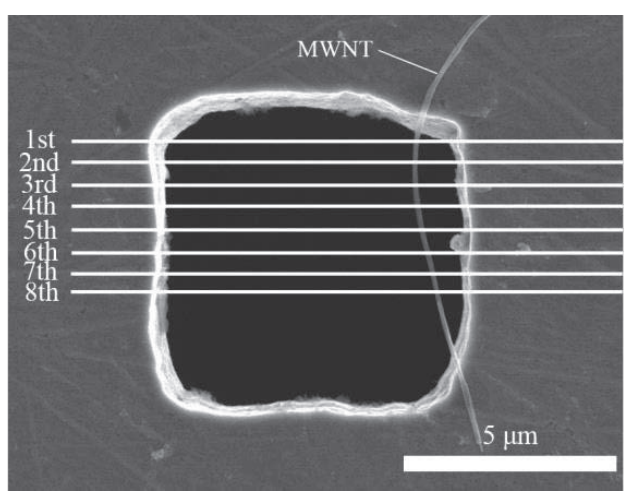

Fig. 1 FIB is scanned on the white lines $(0.1 \mu \mathrm{m} \times 20$ $\mu \mathrm{m})$. Eight amorphous regions are made on a MWNT. 

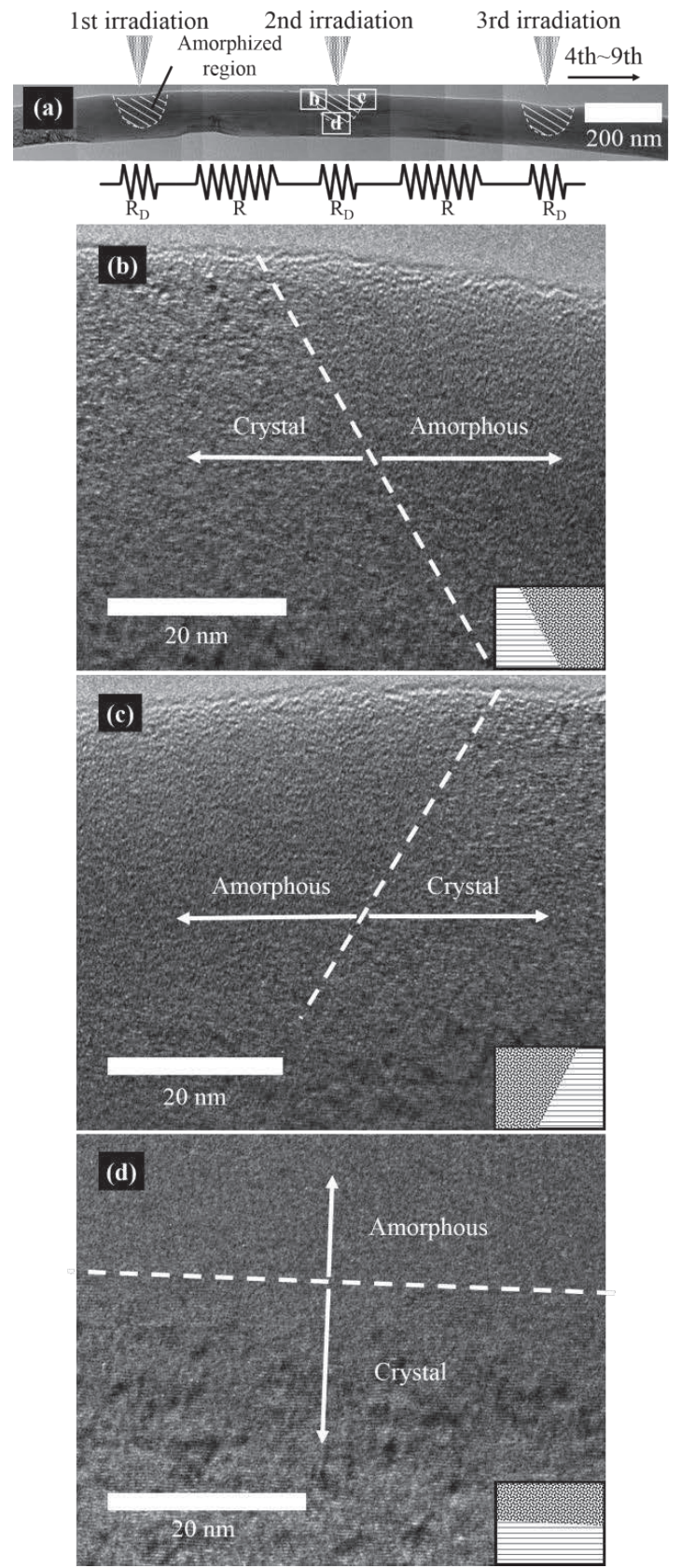

Fig. 2 TEM images of amorphized MWNT due to FIB irradiation. (a) shows the TEM images of the 1st, 2nd and 3rd irradiation position. (b), (c) and (d) show the each boundaries between amorphous and crystal at $2 \mathrm{nd}$ irradiation position. Insets in (b-d) show schematic diagram of each boundaries between crystal and amorphous.

\section{3 熱抵抗の計測原理および手順}

MWNT の熱抵抗を計測する原理を図 3 に示す．このセ ンサは酸化膜付きシリコンウェ八を基板として電子線リ ソグラフィーによる Pt 薄膜のリフトオフ法を中心とした MEMS 技術によって作られ，2つの Pt 電極兼ヒートシン クとその間に渡された Pt ホットフィルム，そして離れた ところにあるもう 1 つのヒートシンクから構成されてい る. ホットフィルム部は基板から $1 \mu \mathrm{m}$ 程度浮いておりそ の大きさは，長さ $9.5 \mu \mathrm{m} ，$ 幅 $500 \mathrm{~nm}$ ，厚さ $40 \mathrm{~nm}$ 程度で ある. Pt ホットフィルムを通電加熱すると，上に凸の放物 形の温度分布が生じる．MWNT をホットフィルムとヒー トシンクの間に懸架すると，ホットフィルムで発生した 熱の一部は MWNT を伝ってヒートシンク側へ流れるた め, 温度分布が図のように変化する。直流電源(Advantest R6243)とデジタルマルチメータ(Keithley 2002) と標準抵抗 (Yokogawa 2792A06)を用いた四端子法によってこれらホ ットフィルムの温度上昇量の平均をホットフィルムの電 気抵抗の変化として読夕取り，MWNT への熱流を 1 次元 定常熱伝導方程式によって解析することで MWNT の熱 抵抗が導出できる[8]. ここで, フォノンの弾道性を考慮し た熱伝導率を想定することで，拡散的輸送を基本とする モデルからサイズ効果の現れる材料の熱輸送を議論する ことに問題はない，ということを付記しておく.

この後，ホットフィルムとヒートシンクの間に懸架さ れた状態の MWNT に垂直に FIB を走査する。本研究て は，約 $10 \mu \mathrm{m}$ の MWNT を 10 等分，あるいは 4 等分する 位置に FIB を照射し，実験を行った（図 3 は 4 等分の場 合) . 両者ともホットフィルム側からヒートシンク側へと 順番に照射位置を移動させる．照射が一度終わると熱抵 抗の計測を行う。これを繰り返すことで FIB の照射回数 に対する欠曜部を含んだ MWNT 全体の熱抵抗の変化の データを得る。

計測用基板の温度はペルチェ素子付きのステージによ

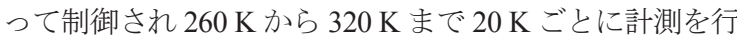
った。また，チャンバーは $5.0 \times 10^{-4} \mathrm{~Pa}$ 程度の真空に保た れることから周囲一の熱伝導と対流による熱損失は大気 圧時に比べ数桁小さくなり, 通電加熱によるホットフィ ルムの温度上昇は $10 \mathrm{~K}$ 以下であることから輻射による熱 損失も発熱量全体の約 $0.01 \%$ 程度となるため考慮しなく てよい. 


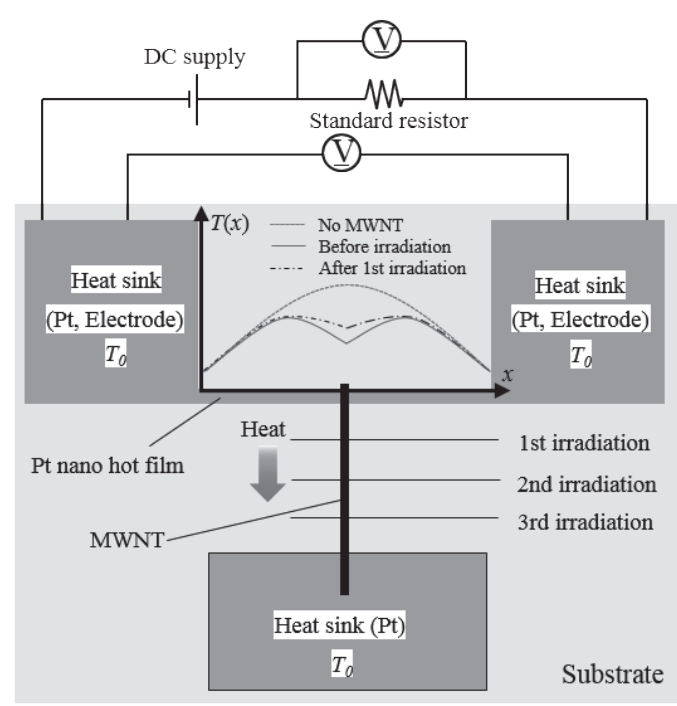

Fig. 3 Schematic of diagram of measurement.

\section{3. 実験結果および考察}

MWNT の熱抵抗は照射回数が増えるに従って当然であ るが増加した. $300 \mathrm{~K}$ における FIB の照射回数に対する熱 抵抗の変化を図 4 に示寸. エラーバーは寸法や抵抗温度 係数等の誤差を計算し評価したものである. 図 4 中の I, Iはそれぞれ 10 等分と 4 等分になる位置に照射したデー タであり，IIIは 16 等分を狙った[2]のデータである. 計測 機器や計測温度を, ドーズ量を始めとする実験条件は I, II と同じである. ただし，I では照射 6 回目以降のデータ は得られておらず，IIIではFIB 照射の順番が I ，II とは異 なっており, 最初に 2 等分, 次の 2 回で 4 等分, 次の 4 回 で 8 等分, そして次の 8 回で 16 等分する位置へ照射して いる. TEM 観察から見積もった欠陥 1 個の大きさはそれ ぞれ MWNT の体積の $0.21 \%$ （I ），0.21\%（II），0.41\% （III）を占め, 図 4 から欠陥の体積比率に比べて熱抵抗の 増加率がはるかに大きいことがわかる. 各 MWNT の直径 と長さはそれぞれ I では $90 \mathrm{~nm}$ と $10.1 \mu \mathrm{m}$, II では $87 \mathrm{~nm}$ と $10.1 \mu \mathrm{m}, \mathrm{III}$ では $85 \mathrm{~nm}$ と $4.8 \mu \mathrm{m}$ である. なお，長さと はホットフィルムとヒートシンク間に渡された MWNT の懸架部分の長さを意味する. 3 種類の実験は照射の順番 や位置が異なることで, 久陥部によって MWNT を分割し た時の長さを変えることができ，ここから熱伝導率の長 さ依存性の調查が可能になる.

照射回数 0 , 寸なわち照射前の I, II， III を比較すると 熱抵抗の絶対值が異なっている。これは長さが違うこと
に加えて，MWNT 合成時にできた格子久陥の度合いが異 なるためと考えている. なお， I が特に大きな熱抵抗を示 している原因はホットフィルムとヒートシンクへの MWNT の接触がよくないことが考えられるが, 以下の議 論において大きな問題とはならない.

ここで，各照射前後での熱抵抗の増加量（図 5）に注目 すると，I，II， IIIに共通して 1 回目の照射後の熱抵抗の 増加量が最大であり, 照射回数が増えるにつれて熱抵抗 の増加量が減少していることがわかる。もし MWNT での 熱輸送がマクロな材料と同様に拡散的に生じていると仮 定すると, 図 2 (a) に示したような熱抵抗の直列接続で 解釈でき, 増加量は一定となるはずであるので, この結果 は欠陥がすべてほぼ同じ大きさであるという TEM 観察結 果と矛盾する. この矛盾は MWNT が有する大きな異方性 [10]を考慮しても変わることはなく, すなわち拡散的な熱 輸送という仮定が詋りであると結論できる. なお, 図 5 は 図 4 の熱抵抗の増加量減少の傾向だけを表したものであ り, エラーバーを表示していない.

そこで, 準弾道的な熱輸送, すなわち, 熱伝導率が長さ によって変化すると仮定して考察する.このモデルは[2] で用いられているもので, TEM と組み合わせることで熱 伝導率の試料の長さに対する依存性を考えることができ る. II で MWNT が欠陥部によって 4 等分されている 3 回 目照射後を例にとる. このとき，MWNT の全熱抵抗を長 さ $2.5 \mu \mathrm{m}$ の FIB を照射していない部分 4 個と欠陥部 3 個 の熱抵抗の連結と考えると, 計測した MWNT の全熱抵抗 と仮定した欠陷部の熱抵抗 $\left(2.4 \times 10^{5} \mathrm{~K} \cdot \mathrm{W}^{-1}\right)$ から長さ 2.5 $\mu \mathrm{m} の$ MWNT の熱抵抗が求められ, 熱伝導率が導出でき る. 欠陥部の熱抵抗は, 結晶構造が残っている箇所を熱の 主な輸送路と考えて[11], TEM 観察から見積もった欠陥 部の長さと結晶構造が残っている箇所の断面積に FIB 照 射前の MWNT の熱伝導率を合わせることで仮定した。こ の方法をすべての照射段階において適用することで図 6 を得た. 図 6 には久陷部の熱抵抗を II と同様に $1.2 \times 10^{5} \mathrm{~K}$. $\mathrm{W}^{-1}$ と仮定したIIIの熱伝導率の長さ依存性[2]も加えてい る. 重要な点はどちらの熱伝導率も試料の長さの増大に 伴って収束する様子は無いことであり, このことは MWNT よりもフォノンの自由行程が長い SWNT におい て数 $\mu \mathrm{m}$ の領域ではすでに準弾道的な熱輸送に遷移して いるという数值計算の結果 $[5,6]$, および, MWNT におけ る平均自由行程を $50 \mathrm{~nm}$ と見積もった実験結果 [9]から考 えて不自然である. なお, [2]で計算されているように, 熱 
抵抗の值を $1.2 \times 10^{5} \mathrm{~K} \cdot \mathrm{W}^{-1}$ 以外とした計算によっても収 束しない傾向は変わらない. これらから, 今回の実験にお ける MWNT の分割を単純にフォノンの平均自由行程の 短縮ととらえるモデルは正しくないと言える.

以上より, FIB 照射による MWNT の熱抵抗の増加量の 変化は拡散的ではなく, 熱伝導率が長さのべき乗に比例 するというモデルによっても表現することはできないこ とが確認できた. この現象の理解のためには, フォノンの 弾道性を含み，かつ欠陥の数に対して依存寸る要因を考 えなければならない. 例えば, 試料中に 1 万所でも欠陥が 入ることで熱輸送に大きく寄与するフォノンが消滅する ことが考えられるが, 結論は MWNT においてもフォノン の分散関係を精密に導出するほどに理論研究が進展する のを待つ必要がある。

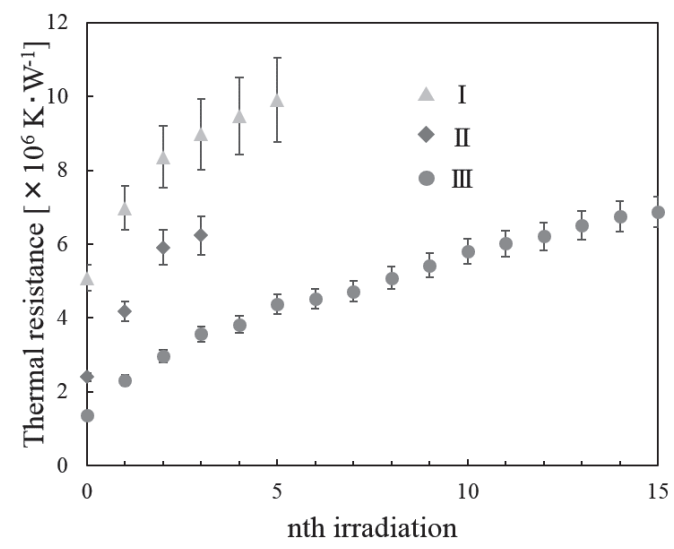

Fig. 4 Thermal resistance of FIB-irradiated MWNTs.

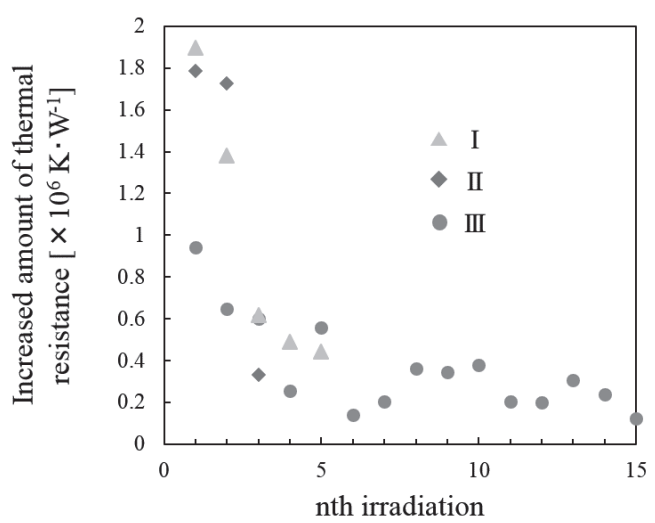

Fig. 5 Increased amount of thermal resistance of FIBirradiated MWNTs.

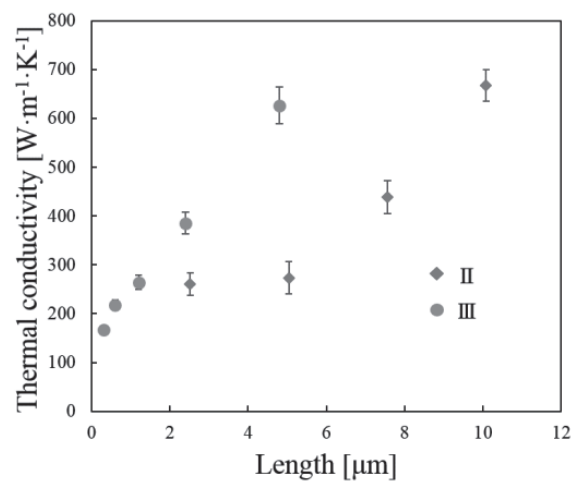

Fig. 6 The length dependence of thermal conductivity.

\section{4. 結 論}

本研究では, FIB 照射によって複数の欠陥が入った MWNT の熱抵抗の計測を行い，以下の結論が得られた.

1.MWNTに FIB 照射を行うと，照射回数とともに全熱 抵抗は増加する一方で, その増加量は 1 回目の照射時が 最大であり，その後減少する.

2. FIB を照射した MWNT 内の熱輸送は拡散的ではない ことが確かめられた. しかしながら, これまで用いられて きた準弾道性のモデル $\left(k \propto L^{\beta}\right)$ でも実験結果を表現でき なかった。

\section{[謝辞]}

本研究の実施の一部に関して, 科学研究費補助金 24560237，25289041，26289047，26630067 および JST・ CREST から助成を受けた。 また, 研究の遂行に際して, 林浩之氏および清華大学 Xing Zhang 教授, Qin-Yi Li 氏に 多くの有用な助言を受けた. TEM 観察には九州大学超顕 微解析研究センターの装置を用いた。ここに記して謝意 を表す。

\section{参考文献}

[1] C. W. Chang, D. Okawa, H. Garcia, A. Majumdar, A. Zettl; "Breakdown of Fourier's Law in Nanotube Thermal Conductors", Phys. Rev. Lett. , 101 (2008) 075903.

[2] H. Hayashi, K. Takahashi, T. Ikuta, T. Nishiyama, Y. Takata $\mathrm{X}$. Zhang; "Direct evaluation of ballistic phonon transport 
in a multi-walled carbon nanotube”, Appl. Phys. Lett. , 104 (2014) 113112.

[3] T. K. Hsiao, H. K. Chang, S. C. Liou, M. W. Chu, S. C. Lee, C. W. Chang; "Observation of Room-temperature Ballistic Thermal Conduction Persisting over $8.3 \mu \mathrm{m}$ in SiGe Nanowires", Nature Nanotech., 8 (2013) 534.

[4] S. Maruyama; "A Molecular Dynamics Simulation of Heat Conduction in Finite Length SWNTs", Physica B. , 323 (2002) 193-195.

[5] T. Yamamoto, S. Konabe, J. Shiomi, S. Maruyama; "Crossover from Ballistic to Diffusive Thermal Transport in Carbon Nanotubes", Appl. Phys. Express, 2 (2009) 095003.

[6] C. Selvik, H. Sevincli, G. Cuniberti, T. Cagin; "Phonon Engineering in Carbon Nanotubes by Controlling Defect Concentration", Nano Lett. , 11 (2011) 4971-4977.

[7] E. Pop, D. Mann, Q. Wang, K. Goodson, H. Dai; “Thermal conductance of an individual single-wall carbon nanotube above room temperature", Nano Lett. , 6 (2006) 96-100.

[8] M. Fujii, X. Zhang, H. Xie, H. Ago, K. Takahashi, T. Ikuta, H. Abe, T. Shimizu; "Measuring the Thermal Conductivity of a Single Carbon Nanotube", Phys. Rev. Lett. , 95 (2005) 065502.

[9] T. Y. Choi, D. Poulikakos, J. Tharian, U. Sennhauser; "Measurement of the Thermal Conductivity of Individual Carbon Nanotubes by the Four-Point Three- $\omega$ Method", Nano Lett. , 6 (2006) 1589-1593.

[10] H. Hayashi, T. Ikuta, T. Nishiyama, K. Takahashi; "Enhanced Anisotropic Heat Conduction in Multi-walled Carbon Nanotubes”, J. Appl. Phys., 113 (2013) 014301.

[11] K. Takahashi, N. Hilmi, Y. Ito, T. Ikuta, X. Zhang; "Measurement of the Thermal Conductivity of Nanodeposited Material", Int. J. Thermophys. , 30 (2009) 1864-1874.

[Received Apr. 1, 2015, Accepted Aug. 27, 2015] 